\title{
Prevalence of hypertension and its associated risk factors among bank workers of Kathmandu
}

\author{
Chataut J' ID $ه$, Dahal S ${ }^{2}$, Shrestha A ${ }^{3}$ iD, Bhandari MS ${ }^{4}$ iD
}

1Jagdish Chataut, Associate Professor; ${ }^{2}$ Sumira Dahal, Resident; ${ }^{3}$ Abha Shrestha, Lecturer; ${ }^{4}$ Mukta Singh Bhandari, Assistant Professor, Department of Community Medicine, Kathmandu University School of Medical Sciences, Kavre, Nepal.

\begin{abstract}
Background: Bank workers are exposed to risk factors which make them a potential occupational risk group for hypertension and information on the prevalence and risk factors of hypertension among bank workers in Nepal is very scarce.

Objective: The aim of the study was to estimate the prevalence and associated factors of hypertension among bank employees in Kathmandu district.

Methodology: A descriptive cross-sectional study was conducted among 416 bank employees of commercial banks of Kathmandu district. The information was obtained using a self-administered questionnaire in the workplace which included demographic information of individuals and other risk factors like alcohol,tobacco use and physical activity. Anthropometric measurements and blood pressure were recorded and hypertension was defined as per Joint National Committee VII criteria. Data analysis was performed using the Statistical Program for Social Sciences version 23.

Results: Prevalence of hypertension was found to be $11.3 \%$. Of the 47 participants with hypertension, 40(85.1\%) were known cases while $7(14.9 \%)$ were newly diagnosed. Age, gender, marital status, overweight (BMI $\geq 25)$, smoking, alcohol consumption, having diabetes, and family history of -hypertension were found to have significant association with hypertension in univariate analysis. The multivariate logistic regression analysis revealed that gender, having diabetes and physical activity had independent and significant association with hypertension.

Conclusion: Based on the findings from the study, we can conclude that hypertension is significantly associated with gender, physical activity and diabetes. Measures for early detection of hypertension and diabetes are required and health education regarding lifestyle modifications is recommended.
\end{abstract}

Key words: Hypertension; Occupational; Prevalence; Risk factors.

Access this article online

Website: www.jkmc.com.np

DOI: https://doi.org/10.3126/jkmc.v9i2.35531

\section{HOW TO CITE}

Chataut J, Dahal S, Shrestha A, Bhandari MS. Prevalence of Hypertension and associated risk factors among bank workers in Kathmandu. J Kathmandu Med Coll. 2020;9(2):107-13.

Address for correspondence

Dr. Jagdish Chataut

Associate Professor, Department of Community Medicine,

Kathmandu University School of Medical Sciences

Postal Address: GPO Box 11008, Kathmandu, Nepal

E-mail: jagdish_chataut@yahoo.com

Copyright $\odot 2020$ Journal of Kathmandu Medical College (JKMC) ISSN: 2019-1785 (Print), 2091-1793 (Online)

(7) (8) This work is licensed under a Creative Commons Attribution-Non Commercial 4.0 International License.

\section{INTRODUCTION}

ardiovascular diseases(CVD) cause 18 million deaths annually worldwide ${ }^{1}$. Hypertension (HTN) is the leading global risk factor for $\mathrm{CVD}^{2}$ and is now regarded as the major cause of premature death worldwide ${ }^{3}$. Hypertension is now an important issue in low- and middle-income countries and there is high prevalence of hypertension in developing countries as compared to developed countries these days ${ }^{3-6}$.

Epidemiological studies have shown that sedentary lifestyle, obesity and stress are significant risk factors for hypertension ${ }^{3,7}$. As bank workers are exposed to these risk factors, it makes them a potential occupational risk group for hypertension and it is important to do screening for hypertension among them ${ }^{8-12}$.Information on the prevalence and risk factors of hypertension among bank workers in Nepal are very limited hence this study is conducted to estimate the prevalence of hypertension 
among bank workers in Kathmandu district and find its risk factors.

\section{METHODOLOGY}

A descriptive cross-sectional study was conducted among bank workers of commercial banks of Kathmandu district to estimate the prevalence of hypertension and its risk factors. The study population consisted of bank workers who had spent at least one year on their job. Pregnant women were excluded from the study. Ethical approval was taken from the Institutional Review Committee of Kathmandu University School of Medical Sciences. Kathmandu district was selected purposively as head offices of all commercial banks are located in Kathmandu district, so that no banks were missed. Both government and private commercial banks were included in the study. There are a total 27 banks in Nepal,out of which 2 banks refused to participate in the study.

The sample size 417 was estimated by using formula $n$ $=z^{2} \mathrm{pq} / \mathrm{d}^{2}$ at $95 \%$ Confidence interval (Z), with expected prevalence (p) of $44 \%{ }^{13}$ and relative precision (d) of $5 \%$ with addition of $10 \%$ non-response rate. The samples were selected according to the proportion of bank workers in each bank using Probability Proportional to size (PPS) sampling method. From each bank required sample was selected using simple random sampling method.

An informed consent was read and explained to the participants and the consent was obtained. Data on baseline characteristics and risk factors were collected using self-administered questionnaire in the workplace. Height, weight, and blood pressure of each participant was measured.

Height was measured with a portable standard stature scale, without footwear, with participants standing on a flat surface facing the interviewer with their feet together and heels against the backboard with knees straight. Height was recorded in centimeters. Weight was measured with a portable digital weighing scale. The instrument was placed on a firm, flat surface. Weight was measured with minimum cloths and no footwear, with participants standing on the scale face forward and arms placed at their side. Weight was recorded in kilograms.

Body mass index (BMI) was calculated using formula, weight in kilograms divided by the square of the height in meters. Overweight was defined as BMI $\geq 25$.

Blood pressure was measured following standard protocol with a digital, automated blood pressure monitor (OMRON HEM - 8712). Three readings of blood pressure were obtained and the mean of the second and third readings were calculated. Hypertension was defined as having systolic blood pressure $\geq 140 \mathrm{mmHg}$ and/or diastolic blood pressure $\geq 90 \mathrm{mmHg}$ during the study as recommended by Joint National Committee 7, and the participants who were taking anti-hypertensive medicines were also considered as hypertensive ${ }^{14}$. Smoker was defined as those who were smoking cigarettes and those who quit less than one month before the interview. Any participant who drank alcohol within the last 30 days of data collection was defined as current alcohol user. Participants were categorized as physically active if they were involved in any type of physical activity (walking, jogging, sports, yoga) for at least 30 minutes per day on most of the days of the week.The collected data was analyzed using Statistical Program for Social Science(SPSS) version 23. Sample characteristics were described using mean and standard deviation for continuous variable and percentage for categorical variable. Chi-square test was used to test the differences between proportions. All the covariates (age, gender, marital status, BMI, smoking, alcohol, diet, physical activity, diabetes, family history of hypertension and mode of travel) were included as independent variables for multiple logistic regression analysis to identify the factors independently associated with hypertension. A $p$-value $<0.05$ was considered as statistically significant.

\section{RESULTS}

A total of 416 individuals from 25 commercial banks participated in the study. Socio-demographic characteristics of the study population is provided in Table 1. A majority $(247,60.3 \%)$ of the participants were in the age group of 31-40 years, males were more than females (214 Vs 202). A total of 115 (27.6\%) participants reported to be smokers and $176(42.3 \%)$ to be alcohol consumers. Majority of the participants reported not having diabetes $(94.5 \%)$ and family history of hypertension (66.1\%). Only $27.5 \%$ were engaged in physical exercise and the most common mode of travel was by motorbike.

Of the total 416 participants, $47(11.3 \%)$ were classified as hypertensive and $87(20.9 \%)$ were pre-hypertensive (Table 2). Of the 47 hypertensive, $40(85.1 \%)$ were known hypertensives while $7(14.9 \%)$ were newly diagnosed at the time of data collection using JNC 7 criteria.

Out of all the factors that were assessed in this study; age, gender, marital status, overweight (BMI $\geq 25$ ), smoking, alcohol consumption, having diabetes, and family history of HTN were found to have significant association with 
hypertension in univariate analysis considering $\mathrm{p}<0.05$

(Table 3).

The multivariate logistic regression analysis revealed that gender, having diabetes and physical activity have independent and significant association with hypertension. Result indicate that male gender have higher odd of having hypertension compared to female gender (AOR: 3.01, 95\% Cl: 1.07-8.52; $\mathrm{p}=0.03$ ), hypertension tends to decrease with increase in physical activity (AOR: 0.33, 95\% Cl: 0.133-0.836; $\mathrm{p}=0.01$ ) and individuals with diabetes have higher odd of having hypertension (OR: 4.42, 95\% Cl: 1.47-13.33; $\mathrm{p}<0.001$ ) (Table 4).

Table 1: Characteristics of the participants $(n=416)$

\begin{tabular}{|c|c|c|}
\hline Characteristics & Categories & n (\%) \\
\hline \multirow{3}{*}{ Age (years) } & $21-30$ & $144(34.6)$ \\
\hline & $31-40$ & $247(59.3)$ \\
\hline & $>40$ & $25(6.1)$ \\
\hline \multirow{2}{*}{ Gender } & Female & $202(48.5)$ \\
\hline & Male & $214(51.5)$ \\
\hline \multirow{2}{*}{ Marital Status } & Married & $142(34.2)$ \\
\hline & Unmarried & $274(65.8)$ \\
\hline \multirow{2}{*}{ BMI } & $<25$ & $271(65.2)$ \\
\hline & $\geq 25$ & $145(34.8)$ \\
\hline \multirow{2}{*}{ Smoking } & No & $301(72.4)$ \\
\hline & Yes & $115(27.6)$ \\
\hline \multirow{2}{*}{ Alcohol consumption } & No & $240(57.7)$ \\
\hline & Yes & $176(42.3)$ \\
\hline \multirow{2}{*}{ Diet } & Vegetarian & $73(17.6)$ \\
\hline & Non vegetarian & $343(82.4)$ \\
\hline \multirow{2}{*}{ Physical activity } & No & $302(72.6)$ \\
\hline & Yes & $114(27.4)$ \\
\hline \multirow{2}{*}{ Diabetes } & No & $393(94.5)$ \\
\hline & Yes & $23(5.5)$ \\
\hline \multirow{2}{*}{ Family H/O HTN } & No & $275(66.1)$ \\
\hline & Yes & $141(33.9)$ \\
\hline \multirow{4}{*}{ Mode of travel } & Walk & $36(8.6)$ \\
\hline & Public transport & $62(14.9)$ \\
\hline & Bike & $285(68.6)$ \\
\hline & Car & $33(7.9)$ \\
\hline
\end{tabular}

Table 2: Distribution of Hypertension according to JNC 7 Classification $(n=416)$

\begin{tabular}{lcc}
\hline \multicolumn{1}{c}{ Hypertension } & Frequency & Percentage \\
Normal & 282 & 67.8 \\
Pre-hypertension & 87 & 20.9 \\
Stage 1 & 47 & 11.3 \\
\hline
\end{tabular}


Table 3: Prevalence of Hypertension according to the studied risk factors

\begin{tabular}{|c|c|c|c|c|}
\hline \multirow[t]{2}{*}{ Variables } & \multirow[t]{2}{*}{ Categories } & \multicolumn{2}{|c|}{ Participants with Hypertension } & \multirow[t]{2}{*}{ p-value } \\
\hline & & Yes (\%) & No $(\%)$ & \\
\hline \multirow{3}{*}{ Age } & $21-30$ & $2(1.4)$ & $142(98.6)$ & \multirow{3}{*}{$<0.001$} \\
\hline & $31-40$ & $36(14.6)$ & $211(85.4)$ & \\
\hline & $>40$ & $9(36)$ & $16(64)$ & \\
\hline \multirow{2}{*}{ Gender } & Female & $8(4)$ & $194(96)$ & \multirow{2}{*}{$<0.001$} \\
\hline & Male & $39(18.2)$ & $175(81.8)$ & \\
\hline \multirow{2}{*}{ Marital Status } & Unmarried & $4(2.8)$ & 138(97.2) & \multirow[b]{2}{*}{$<0.001$} \\
\hline & Married & $43(15.7)$ & $231(84.3)$ & \\
\hline \multirow[b]{2}{*}{ BMI $\left(\mathrm{kg} / \mathrm{m}^{2}\right)$} & $<25$ & $14(5.2)$ & $257(94.8)$ & \multirow[b]{2}{*}{$<0.001$} \\
\hline & $\geq 25$ & $33(22.7)$ & $112(77.3)$ & \\
\hline \multirow{2}{*}{ Smoking } & No & $24(8)$ & $277(92)$ & \multirow[b]{2}{*}{$<0.001$} \\
\hline & Yes & $23(20)$ & $92(80)$ & \\
\hline \multirow{2}{*}{ Alcohol } & No & $29(12.1)$ & 147(87.9) & \multirow[b]{2}{*}{$<0.05$} \\
\hline & Yes & $18(10.2)$ & $222(89.8)$ & \\
\hline \multirow{2}{*}{ Diet } & Vegetarian & $6(8.2)$ & $67(91.8)$ & \multirow{2}{*}{.422} \\
\hline & Non-vegetarian & $41(12)$ & $302(88)$ & \\
\hline \multirow{2}{*}{ Physical activity } & No & 39(12.9) & $263(87.1)$ & \multirow[b]{2}{*}{.117} \\
\hline & Yes & $8(7)$ & 106(93) & \\
\hline \multirow{2}{*}{ Diabetes } & No & $37(9.4)$ & $356(90.6)$ & \multirow[b]{2}{*}{$<0.001$} \\
\hline & Yes & $10(43.5)$ & $13(56.5)$ & \\
\hline \multirow{2}{*}{ Family H/O HTN } & No & $24(8.7)$ & 251(91.3) & \multirow[b]{2}{*}{.032} \\
\hline & Yes & $23(16.3)$ & 118(83.7) & \\
\hline \multirow{4}{*}{ Mode of travel } & Walk & $2(5.5)$ & $34(94.5)$ & \multirow{4}{*}{.055} \\
\hline & Public vehicle & $2(3.2)$ & $60(96.8)$ & \\
\hline & Bike & $37(13)$ & $248(87)$ & \\
\hline & Car & $6(18.2)$ & $27(81.8)$ & \\
\hline
\end{tabular}

Table 4: Risk factors of hypertension: Multiple logistic regression analysis

\begin{tabular}{|c|c|c|c|c|c|}
\hline Variables & Categories & Number & OR & 95\% Confidence Interval & p-value \\
\hline \multirow{3}{*}{ Age (years) } & $21-30$ & 144 & Ref & Ref & \multirow{3}{*}{0.13} \\
\hline & $31-40$ & 247 & 3.60 & $0.68-19.04$ & \\
\hline & $>40$ & 25 & 7.49 & $1.03-54.30$ & \\
\hline \multirow[t]{2}{*}{ Gender } & Female & 202 & Ref & Ref & \multirow{2}{*}{0.03} \\
\hline & Male & 214 & 3.01 & $1.07-8.52$ & \\
\hline \multirow{2}{*}{ Marital Status } & Unmarried & 142 & Ref & Ref & \multirow{2}{*}{0.32} \\
\hline & Married & 274 & 1.90 & $0.53-6.81$ & \\
\hline \multirow[t]{2}{*}{ BMI $\left(\mathrm{kg} / \mathrm{m}^{2}\right)$} & $<25$ & 271 & Ref & Ref & \multirow{2}{*}{0.40} \\
\hline & $\geq 25$ & 145 & 2.35 & $2.34-1.04$ & \\
\hline \multirow{2}{*}{ Smoking } & No & 301 & Ref & Ref & \multirow{2}{*}{0.35} \\
\hline & Yes & 115 & 1.51 & $0.63-3.61$ & \\
\hline \multirow{2}{*}{ Alcohol } & No & 240 & Ref & Ref & \multirow{2}{*}{0.45} \\
\hline & Yes & 176 & 1.37 & $0.60-3.13$ & \\
\hline \multirow{2}{*}{ Diet } & Vegetarian & 73 & Ref & Ref & \multirow{2}{*}{0.37} \\
\hline & Non vegetarian & 343 & 1.64 & $0.55-4.83$ & \\
\hline
\end{tabular}




\begin{tabular}{cccccc}
\hline \multirow{2}{*}{ Physical activity } & No & 302 & Ref & Ref & 0.01 \\
& Yes & 114 & 0.33 & $0.133-0.836$ & Ref \\
Diabetes & No & 393 & Ref & $1.47-13.33$ & $<0.001$ \\
& Yes & 23 & 4.42 & Ref & 0.15 \\
\hline \multirow{2}{*}{ Family h/o HTN } & No & 275 & Ref & $6.82-3.58$ & \\
& Yes & 141 & 1.71 & Ref & \\
\multirow{5}{*}{ Mode of travel } & Walk & 36 & Ref & $0.43-16.37$ & 0.33 \\
& Public vehicle & 62 & 2.64 & $0.48-31.25$ & \\
& Bike & 285 & 3.87 & $0.82-8.403$ & \\
\hline
\end{tabular}

\section{DISCUSSION}

This study conducted among 416 bank employees of Kathmandu district revealed that prevalence of hypertension was $11.3 \%$ which is comparable to the study done in Owerri, Nigeria, which reported prevalence of hypertension among bank workers as $12.4 \%{ }^{15}$. Prevalence of hypertension among bank workers is less compared to prevalence in general population of Nepal as systematic review and nationwide survey found prevalence of hypertension in general population to be $28.4 \%$ and $26 \%$ respectively ${ }^{16,17}$. There are other studies which reported much higher prevalence compared to our findings, Gujrat $(30.4 \%)^{9}$, Uttar Pradesh $(69.5 \%)^{10}$, Karnataka $(31 \%)^{12}$, Puducherry $(44.3 \%)^{13}$, Nigeria $(34.4 \%)^{18}$, Russia $(35.2 \%)^{19}$. Our study also found that males have significantly higher prevalence of hypertension than females. This finding is consistent with findings from other studies done on bank workers $9,12,20-23$. However there are studies which fail to establish a significant association between gender and hypertension ${ }^{24,25}$.Prevalence of hypertension among males is higher than in females in general population of Nepal ${ }^{16,17}$ which corroborates with our study finding. Significant association was found between physical activity and hypertension in this study and similar findings were reported by many other studies ${ }^{9,12,13}$. However, some studies have shown no significant association between physical activity and hypertension ${ }^{20,26}$. Our findings revealed that hypertension is significantly higher among participants with known history of diabetes as had been reported by other studies ${ }^{10,25}$. Unlike our findings Ismail et.al ${ }^{24}$ in their study on bank workers reported no association between diabetes and hypertension. In contrast to our study findings, some of the previous studies reported that smoking ${ }^{20}$ and alcohol ${ }^{23}$ were significantly associated with hypertension. However, we believe that quantification of their usage would provide better insight into association between them.

Even though our study found comparatively low (11.3\%) prevalence of hypertension, prevalence of prehypertension was high (20.9\%). Individuals in the prehypertension category are at high risk of developing hypertension and should be advised to practice lifestyle modification in order to reduce their risk of developing hypertension in the future ${ }^{14}$. Our study has certain limitations. The study is cross-sectional, hence causal relationship between exposure and outcome cannot be established. The majority of the answers were selfreported which may lead to over reporting or under reporting of co-morbid illness, alcohol consumption, smoking status etc.

\section{CONCLUSION}

Based on the findings from the current study we can conclude that hypertension is significantly associated with gender, physical activity, and diabetes. We also found that $20.9 \%$ of the participants were classified as pre-hypertensive, which adds to the overall future risk of developing hypertension. Measures for early detection of hypertension and diabetes are required and health education regarding lifestyle modifications is recommended in reducing and controlling the prevalence of hypertension.

Conflict of interest: None Source(s) of support: None 


\section{REFERENCES}

1. NCD Risk Factor Collaboration (NCD-RisC). Worldwide trends in blood pressure from 1975 to 2015: a pooled analysis of 1479 population-based measurement studies with 19.1 million participants. Lancet. 2017;389(10064):37-55. [Pub Med | Full Text | DOI]

2. Cardiovascular disease, chronic kidney disease, and diabetes mortality burden of cardio-metabolic risk factors from 1980 to 2010: A comparative risk assessment. The Lancet Diabetes and Endocrinology, 2014;2, 634-47. [Pub Med | Full Text | DOI]

3. World Health Organization. Hypertension [Internet]. [ cited 2020 March 20] [Full Text]

4. Nissien A, Bothig S, Grenroth H, Lopez AD. Hypertension in developing countries. World Health Stat Q. 1988;41:141-54. [Full Text]

5. Bacha D, Abera H. Knowledge, attitude and selfcare practice towards control of hypertension among hypertensive patients on follow-up at St. Paul's Hospital, Addis Ababa, Ethiopia. J Health Sci. 2019; 29: 421-30. [Pub Med | Full Text | DOI]

6. Mittal BV, Singh AK. Hypertension in the Developing World: Challenges and Opportunities. American Journal of Kidney Diseases. 2010;55(3):590-98. [Full Text | DOI]

7. Bhadoria AS, Kasar PK, Toppo NA, Bhadoria P, PradhanS, Kabirpanthi V. Prevalence of hypertension and associated cardiovascular risk factors in Central India. J Fam Community Med. 2014;21:29-38. [Pub Med | Full Text | DOI]

8. Guimont C, Brisson C, Dagenais GR, Milot A, Vezina $M$, Masse $B$ et al. Effects of job strain on blood pressure: a prospective study of male and female white-collar workers. American Journal of Public Health. 2006;96(8):1436-43. [ Pub Med | Full Text | DOI]

9. Irfan MM, Desai VK, Kavishwar A. A study on effect of lifestyle risk factors on prevalence of hypertension among white collar job people of Surat. Internet J Occup Health. 2011;1:155-62. [Full Text]

10. Maroof KA, Parashar P, Bansal R, Ahmad S. A study on hypertension among the bank employees of Meerut district of Uttar Pradesh. Indian J Public Health. 2007;51:225-7. [Pub Med | Full Text]

11. Lokare L, Nekar MS, Mulkipatel SY, Venktesh M. Metabolic equivalent task score and risk factors of coronary heart disease in bank employees. Int J Biol Med Res. 2012;3:1627-30. [Full Text]

12. Shivaramakrishna HR, Wantamutte AS, Sangolli HN, Mallapur MD. Risk factors of coronary heart diseases among bank employees of Belgaum city-Cross sectional study. Al Ameen J Med Sci. 2010;3:152-9. [Full Text]

13. Kumar SG, Sundaram ND. Prevalence and risk factors of hypertension among bank employees in urban Puducherry, India. Int J Occup Environ Med. 2014;5:94-100. [Pub Med | Full Text]

14. The Seventh Report of the Joint National Committee on Prevention, Detection, Evaluation, and Treatment of High Blood Pressure. National Heart, Lung and Blood Institute; 2003. [Full Text]

15. Diwe KC, Enwere OO, Uwakwe KA, Duru CB, Chineke HN. Prevalence and awareness of hypertension and associated risk factors among bank workers in Owerri, Nigeria. Int J Med Biomed Res 2015;4(3):14248. [Full Text | DOI]

16. Huang $Y$, Guo P, Karmacharya BM, Seeruttun SR, $\mathrm{Xu}$ DR, Hao Y. Prevalence of hypertension and prehypertension in Nepal: a systematic review and meta-analysis. Glob health res policy 2019;4(11). [Full Text | DOI]

17. Aryal KK, Mehata $S$, Neupane S, Vaidya A, Dhimal $M$, Dhakal $P$, et al. the burden and determinants of non-communicable diseases risk factors in Nepal: Findings froma Nationwide STEPS Survey. PLoS One 2015; 10(8): e0134834 10.1371/journal. pone.0134834. [Pub Med | Full Text |DOI]

18. Salaudeen AG, Musa OI, Babatunde OA, Atoyebi OA, Durowade KA, Omokanye LO. Knowledge and prevalence of risk factors for arterial hypertension and blood pressure pattern among bankers and traffic wardens in Ilorin, Nigeria. African Health Sciences 2014;14(3):593-9. [Pub Med | Full Text | DOI]

19. Konradi AO, Rotar OP, Korostovtseva LS, Ivanenko VV, Solntcev VN, Anokhin SB, et al. Prevalence of metabolic syndrome components in a population of bank employees from St. Petersburg, Russia. Met SyndrRelatDisord. 2011;9(5):337-43[Pub Med |DOI]

20. Brahmankar TR, Prabhu PM. Prevalence and risk factors of hypertension among the bank employees of Western Maharashtra - a cross sectional study. Int J Community Med Publ Health, 2017;4(4):1267-77. [Full Text | DOI]

21. Sumalatha N, Dorle A, Anjum W, Gagan S. Study of Socio-demographic Profile \& Prevalence of Hypertension among Bank Employees in Bagalkot City. Annals of Community Health. 2015;3(1),28-32. [Full Text]

22. Momin MH, Desai VK, Kavishwar AB. Study of sociodemographic factors affecting the prevalence of hypertension among bank employees of Surat City. 
Indian journal of public health, 2012;56(1); 44-8. [Full Text | DOI]

23. Paul PJ, Samson R, William A, Akila B, Purty AJ, Bazroy J. Prevalence and factors associated with hypertension: a community based cross-sectional study among adults in an urban area of Puducherry, South India. Int J Community Med Public Health 2017;4:1620-6.[Full Text | DOI]

24. Ismail IM, Kulkarni AG, Kamble SV, Borker SA, Rekha $\mathrm{R}$, Amruth M. Prevalence of hypertension and its risk factors among bank employees of SulliaTaluk,
Karnataka. Sahel Med J. 2013;16:139-43. [Full Text | DOI]

25. Undhad AM, Bharodiya PJ, Somani RP. Correlates of hypertension among the bank employees of Surat city of Gujarat. National J Comm Med. 2011;2(1):1235.[Full Text | DOI]

26. Yadavannavar MC, Patil SS, VeenaAlgur V. Prevalence of hypertension in some occupational groups of Bijapur city. International Journal of Current Research and Review. 2011;3(8):42-8. [Full Text] 